\title{
Treatment of Acute Myeloid Leukemia Cells In Vitro with a Monoclonal Antibody Recognizing a Myeloid Differentiation Antigen Allows Normal Progenitor Cells to Be Expressed
}

\author{
Irwin D. Bernstein, Jack W. Singer, Robert G. Andrews, Armand Keating, Jerry S. Powell, Barbara H. Bjornson, \\ Janet Cuttner, Vesna Najfeld, Gregory Reaman, Wendy Raskind, David M. C. Sutton, and Philip J. Fialkow \\ Pediatric Oncology Program, Fred Hutchinson Cancer Research Center, Departments of Pediatrics and Medicine, University of \\ Washington, Veterans Administration, Medical Center, Seattle, Washington 98104; Toronto Western Hospital, University of Toronto, \\ Toronto, Ontario, Canada M5G 1X8; Boston City Hospital, Boston University, Boston, Massachusetts 02118; Mt. Sinai Medical Center \\ of the City University of New York, New York 10029; Children's Hospital National Medical Center, Washington, District of Columbia; \\ and the Children's Cancer Study Group, Pasadena, California 91101
}

\begin{abstract}
Monoclonal antibody $\mathrm{LAF3}$ reacts with most acute myeloid leukemia (AML) cells and virtually all normal granulocyte/monocyte colony-forming cells (CFU-GM). Our objective was to determine whether lysis of AML cells with LAF3 and complement allowed expression of normal myeloid progenitors. The five glucose-6-phosphate dehydrogenase (G6PD) heterozygous patients with AML studied manifested only a single G6PD type in blast cells and in most or all granulocyte colony-forming cells, indicating that the leukemias developed clonally. The cells remaining after LAF3 treatment from two of the patients gave rise to granulocytic colonies that expressed the G6PD type not seen in the leukemic clone, indicating that they were derived from normal progenitors (CFU-GM). LAF3-treated cells from these two patients cultured over an irradiated adherent cell layer from normal long-term marrow cultures also gave rise to CFU-GM, which were shown by G6PD analysis to be predominantly nonleukemic. In the other three patients, the progenitor cells remaining after LAF3 treatment were derived mainly from the leukemic clone. The data suggest that in vitro cytolytic treatment with LAF3 of cells from certain patients with AML can enable normal, presumably highly immature progenitors to be expressed.
\end{abstract}

\section{Introduction}

Recently, monoclonal antibodies directed at normal differentiation antigens present on leukemic cells have been prepared (1, 2). Certain of these antibodies have been used therapeutically in an attempt to purge malignant cells from marrow in vitro before autologous marrow transplantation (3-5). The present study was done to determine whether lysis of hematopoietic cells from patients with acute myeloid leukemia (AML) ${ }^{1}$ with a

This work was presented in part at the American Society of Hematology, December 1984; the American Society for Clinical Investigation, June 1985; and the Second International Workshop on Leucocyte Differentiation Antigens, Boston, MA, September 1984.

Address reprint requests to Dr. Bernstein, Pediatric Oncology Department, FHCRC, 1124 Columbia Street, Seattle, WA 98104.

Received for publication 6 June 1986 and in revised form 15 October 1986.

1. Abbreviations used in this paper: AML, acute myeloid leukemia; BFUE, erythroid burst-forming unit; CFU-GM, granulocyte/macrophage colony-forming unit; G6PD, glucose-6-phosphate dehydrogenase.

The Journal of Clinical Investigation, Inc.

Volume 79, April 1987, 1153-1159 monoclonal antibody that recognizes normal colony-forming cells and leukemic blast cells would kill leukemic progenitors without affecting all normal progenitors. This might occur if the leukemia did not involve stem cells that are more primitive than those recognized by the test antibody.

The monoclonal antibody (L4F3) used in these experiments recognizes a myeloid differentiation antigen found on most AML blasts and colony-forming cells as well as on most normal myeloid colony-forming cells, but is not present on the precursors of colony-forming cells detectable in a two-stage long-term marrow cultures system $(2,6-8)$. We determined the effect of L4F3 on circulating hematopoietic progenitor cells from samples of five AML patients heterozygous for glucose-6-phosphate dehydrogenase (G6PD). In such patients, it is possible to determine whether colonies originate from normal or leukemic progenitors. Because of random stable inactivation of one of the two G6PD genes in each somatic cell that occurs as a result of X-chromosome inactivation early in embryogenesis, women heterozygous for the usual G6PD gene $\left(G d^{\mathrm{B}}\right)$, and a variant such as $G d^{\mathrm{A}}$, have two populations of cells, one synthesizing B-type G6PD and the other, A-type enzyme. If a neoplasm is clonal in such a patient, all neoplastic cells will express a single G6PD type, whereas normal tissues will express both A and B G6PD activities.

We have studied 21 G6PD heterozygous patients with AML (9-12, unpublished data), and Ferraris and co-workers $(13,14)$ have reported on three others. In each case, blast cells expressed only a single G6PD enzyme whereas noninvolved tissues, such as skin, manifested both A and B type G6PD. These data indicate that AML develops clonally. Additional studies with G6PD suggest that the leukemia is heterogeneous in the pattern of differentiative expression of its cell of origin. In five G6PD heterozygous patients, red cells and platelets manifested only the single G6PD expressed by the blast cells, indicating that the disease involved a stem cell with multilineage differentiative expression (12-14). In contrast, in 13 other patients, blast cells and cells in the granulocyte/monocyte lineage arose from the leukemic clone, but erythroid cells and platelets were mainly derived from normal stem cells (9-11, 14, and Fialkow et al., unpublished data). These data provide evidence for persistence of normal stem cells in AML and suggest that either the disease arises in a progenitor already committed to the granulocytic/monocytic pathway or in an earlier multipotent stem cell whose differentiative expression is largely restricted to that pathway. Each of the patients in the present study had AML with expression primarily restricted to cells in the granulocytic/monocytic lineage. 


\section{Methods}

Patients. The age of the five patients was in the range of 2.5 to $42 \mathrm{yr}$. At the time of initial study, patients $1,2,3$, and 5 were newly diagnosed and patient 4 was in first relapse. The FAB class of the leukemic cells was M2 for patient 2 and M4 for the other four patients.

Cell preparations. Antibody experiments were performed with cryopreserved peripheral blood cells or, in one experiment, with fresh cells. Samples were drawn into preservative-free heparin and air-expressed to Seattle. Mononuclear cells were separated on Ficoll-Hypaque gradients $(d=1.077)$ and aliquots were cultured for granulocyte/macrophage colony-forming unit (CFU-GM) and erythroid burst-forming unit (BFUE) growth. The remainder of the cells were frozen in the vapor phase of liquid nitrogen in $90 \%$ newborn calf serum with $10 \%$ dimethyl sulfoxide (DMSO). The erythroid cells and granulocytes were separated and tested for G6PD directly as described (9). Samples were obtained according to protocols of the institutional review boards of the referring institutions.

Antibody-dependent complement-mediated cytolysis. The test and control antibodies (L4F3 and T11D7, respectively) used in these studies were in the form of unfractionated ascites fluid; both were of the IgM isotype and were cytotoxic in the presence of complement. The test antibody L4F3 was prepared and characterized as described (6). It recognizes a protein or glycoprotein $M_{\mathrm{r}} 67,000$ probably identical to the antigen detected by the monoclonal antibody MY-9 (15). This antigen is in highest concentration on immature myelocytic cells and on monocytes in marrow and peripheral blood; it is weakly expressed by mature granulocytes and has not been detected on lymphocytes, erythroid cells, or platelets (6). Similar observations have been made with other antibodies thought to react with the same molecule, including L1B2 and MY-9 (6, 15, and Andrews, R., and J. Griffin, personal communication). As a control, cells were treated with an antibody of irrelevant specificity but of similar isotype, the IgM monoclonal antibody T11D7 (anti-mouse Thy-1.1). Hybridoma cells secreting T11D7 were kindly supplied by E. Clark, University of Washington.

$2 \times 10^{6}$ mononuclear cells were incubated for $30 \mathrm{~min}$ at room temperature in $200 \mu$ l of antibody diluted 1:10 ${ }^{3}$ in RPMI 1640 (Gibco, Grand Island, NY) supplemented with $20 \%$ fetal calf serum. $200 \mu \mathrm{l}$ of a 1:2 dilution of prescreened rabbit serum from 17-21-d-old New Zealand white rabbits ( $\&$ \& R Rabbitries, Everett, WA) were added as a source of complement and the incubation was continued for $60 \mathrm{~min}$ at room temperature. Samples were washed three times with RPMI 1640 and suspended in alpha medium (Flow Laboratories, Inc., Inglewood, CA) at $10^{6} \mathrm{cells} / \mathrm{ml}$ based on the number of cells present before antibody treatment.
In vitro culture. Peripheral-blood mononuclear cells were plated for CFU-GM and BFU-E growth in the presence of medium conditioned by T cells stimulated by PHA (PHA-LCM) as described (16). After 12$14 \mathrm{~d}$, the colonies were counted with an inverted microscope, harvested, and individually analyzed for G6PD (9). All colonies or those in a selected area of a plate were selected independent of size (provided they contained $>40$ cells). All colonies were morphologically granulocytic/monocytic or "blastlike."

Two-stage long-term cultures. In this system, test cells are grown over adherent cell layers grown from marrows obtained from normal donors $(7,17)$. After antibody-mediated lysis, $0.5-1.0 \times 10^{6}$ mononuclear cells were placed in a $2.0 \mathrm{ml}$ of suspension culture over irradiated $(800 \mathrm{cGy})$ adherent cell layers from 3-5-wk-old long-term marrow cultures derived from normal donor marrow established in "ambitubes" (Lux Plastics). Cultures treated with as little as $400 \mathrm{CGy}$ fail to produce detectable colonyforming cells (17). Weekly, the cultures were gently agitated by pipetting the supernatant medium several times and then refed after removing one half of the supernatant. The culture medium was McCoy's 5A complete medium supplemented with $12.5 \%$ fetal calf serum, $12.5 \%$ horse serum, and $10^{-6}$ hydrocortisone. Nonadherent cells were washed twice, counted, and plated for CFU-GM growth. The two-stage, long-term cultures were maintained as long as possible but generally were lost after 4-8 wk. When colony-forming cells were grown from these cultures in sufficient numbers, randomly selected colonies were individually plucked and stained with Wright-Giemsa or peroxidase to verify their granulocytic lineage.

\section{Results}

Patients studied. As shown in Table I, normal tissues (skin or $T$ lymphocytes) from the five patients manifested both types of G6PD, but only a single enzyme (A or B) was found in the blast cells, indicating that the leukemias were clonal. CFU-GM from all patients expressed predominantly the G6PD type found in the blast cells. In contrast to the leukemic blast cells, both Aand B-type G6PD were detected in erythroid cells (mature red cells in patients 1,4 , and 5; early erythroid progenitors [BFUE] in patients 2 and 3 ). It is presumed that patients 2 and 3 are $G d^{\mathrm{B}} / G d^{\mathrm{A}-}$ heterozygotes. The $\mathrm{A}^{-}$enzyme is unstable and is usually not detected in mature erythroid cells with the test system we used, but is seen in nucleated red cell precursors, such as BFU-E. The findings of a single G6PD type in leukemic blast

Table I. G6PD in Normal Tissues, Malignant Blast Cells, Red Blood Cells, and Hematopoietic Cell Colonies from Five Patients with AML

\begin{tabular}{|c|c|c|c|c|c|c|c|c|}
\hline \multirow{2}{*}{\multicolumn{2}{|c|}{ Patient }} & \multicolumn{7}{|l|}{ G6PD } \\
\hline & & \multicolumn{3}{|c|}{ Ratio of enzyme type:A to B } & \multicolumn{2}{|l|}{ CFU-GM-derived } & \multicolumn{2}{|l|}{ BFU-E-derived } \\
\hline \multirow[t]{2}{*}{ No. } & Age & Normal tissue* & Blast cells $s^{*}$ & RBC & Colonies per $10^{5}$ & G6PD A to $B$ & Colonies per $10^{5}$ & G6PD A to B \\
\hline & $y r$ & $\%: \%$ & $\%: \%$ & $\%: \%$ & $n$ & & $n$ & \\
\hline 1 & 34 & $60: 40$ & $100: 0$ & $65: 35$ & $549 \pm 63$ & $25: 0$ & $<1$ & $1: 2$ \\
\hline 2 & 42 & $50: 50$ & $0: 100$ & $0: 100$ & $50 \pm 19$ & $5: 15$ & 9 & $6: 5$ \\
\hline 3 & 19 & $30: 70$ & $0: 100$ & $0: 100$ & $15 \pm 2$ & NT & 2 & 9:29 \\
\hline 4 & 18 & $50: 50$ & $0: 100$ & $35: 65$ & $131 \pm 31$ & $0: 15$ & $<1$ & $1: 0$ \\
\hline 5 & 2.5 & $40: 60$ & 100:0 & $50: 50$ & $156 \pm 15$ & $13: 1$ & 13 & $15: 5$ \\
\hline
\end{tabular}

NT, not tested. * Skin (patients 1, 2, and 5) or pooled cultured T lymphocyte colonies (patients 3 and 4). ${ }^{\ddagger}$ Peripheral blood or marrow mononuclear cell preparations consisting predominantly of blast cells. ${ }^{8}$ Erythrocytes (RBC) from patients 3 and 4 were tested after $2 \mathrm{U}$ of packed RBC. The other four patients were tested before transfusion. It is presumed that patients 2 and 3 have the $A^{-}$variant of G6PD; hence, A-type G6PD was not detected in RBC, but was found in nucleated erythroid cells grown in vitro from BFU-E. 
cells and both enzymes in erythroid cells suggest that the differentiative expression of the progenitor cells involved by the leukemias in these patients was mainly restricted to the granulocytic/ monocytic pathway.

Lysis of colony-forming cells. To assay lysis of colony-forming cells, samples were incubated with antibody L4F3, or the control antibody T11D7, in the presence of complement. Treatment with $\mathrm{L} 4 \mathrm{~F} 3$ lysed $96 \pm 4 \%$ (mean \pm standard deviation) and $98 \pm 1 \%$ of CFU-GM from patients 1 and 3, respectively. In contrast, only $49 \%$ and $44 \%$ reductions were observed in patients 4 and 5 , respectively. Two experiments on cells from patient 2 led to a $90 \%$ and $49 \%$ reduction; the first study was performed on fresh cells whereas the second was done with cryopreserved cells. Thus, the lytic effects of antibody L4F3 on CFU-GM were heterogeneous despite the apparently similar levels of stem cell involvement as determined by G6PD expression.

Cells remaining after lysis were plated in semisolid medium and individual colonies were harvested for G6PD analysis to determine whether they originated from malignant or normal stem cells (Table II). In patient 1 , whose leukemic blast cells manifested A-type G6PD, after treatment with control antibody (T11D7) the ratio of G6PD A to B colonies was 88:18, notably different from $A$ to $B$ ratio of $60: 40$ found in normal tissues. In contrast, L4F3-treatment resulted in a colony A to B ratio of 29:16 (pooled results of experiments 1-3). This ratio was similar to that found in normal tissue (skin 60:40) but significantly different from the ratio of $88: 18$ in cells treated with the control

Table II. CFU-GM-derived Colony Growth from Peripheral Blood Mononuclear Cells Treated with Antibody and Complement

\begin{tabular}{|c|c|c|c|c|c|c|}
\hline \multirow[b]{2}{*}{$\begin{array}{l}\text { Patient } \\
\text { no. }\end{array}$} & \multirow[b]{2}{*}{$\begin{array}{l}\text { Leukemic cell } \\
\text { G6PD type }\end{array}$} & \multirow[b]{2}{*}{$\begin{array}{l}\text { Experiment } \\
\text { no. }\end{array}$} & \multicolumn{2}{|l|}{ L4F3 } & \multicolumn{2}{|c|}{ T11D7* } \\
\hline & & & $\begin{array}{l}\text { G6PD } \\
A \text { to } B^{*}\end{array}$ & Inhibition & $\begin{array}{l}\text { G6PD } \\
\text { A to B }\end{array}$ & $\begin{array}{l}\text { Colonies } \\
\text { per } 10^{5}\end{array}$ \\
\hline & & & & $\%$ & & $n$ \\
\hline \multirow[t]{3}{*}{1} & A & 1 & $6: 6$ & 91 & $10: 3$ & $96 \pm 15$ \\
\hline & & 2 & $13: 5$ & $99^{8}$ & $18: 2$ & $60 \pm 5$ \\
\hline & & 3 & $10: 5$ & $97^{8}$ & $60: 13$ & $240 \pm 30$ \\
\hline \multirow[t]{2}{*}{2} & B & 1 & $7: 2$ & $90^{811}$ & $3: 16$ & $4 \pm 3$ \\
\hline & & 2 & $20: 7$ & $49^{8}$ & $4: 10$ & $8 \pm 2$ \\
\hline \multirow[t]{2}{*}{3} & B & 1 & $1: 4$ & 97 & $1: 12$ & $32 \pm 6$ \\
\hline & & 2 & $0: 11$ & 99 & $2: 14$ & $18 \pm 4$ \\
\hline 4 & B & 1 & $0: 14$ & 49 & $0: 14$ & $65 \pm 15$ \\
\hline 5 & A & 1 & $25: 1$ & 44 & $23: 5$ & $57 \pm 13$ \\
\hline
\end{tabular}

* Antibody T11D7 does not recognize hematopoietic cell surface antigens and is included as a control.

${ }^{\ddagger}$ Ratio represents actual number of A-type and B-type colonies harvested. Binding of $L 4 F 3$ to cells from patients 1,3 , and 4 was studied using an indirect immunofluorescence technique as previously described (8). Relatively bright and equivalent staining was observed with cells from patients 1 and 3; minimal staining (homogeneous shift in the fluorescence histogram) was observed with cells from patient 4. Overall differences in ratio of G6PD type A and B colonies between T11D7- and L4F3-treated cells statistically significant $(P=0.017$ for patient 1 and 0.001 for patient 2) (generalized Fisher's exact test for a series of $2 \times 2$ tables) (10).

"Fresh cells, all other experiments were done with frozen cells. antibody T11D7 ( $P \leq 0.017$, generalized Fisher's exact test for a series of $2 \times 2$ tables [18]). In patient 2 , both the leukemic clone and the colonies that were cultured from cells exposed to control antibody T11D7 were type B G6PD. In contrast, after treatment with L4F3 most of the colonies manifested A-type enzyme. This expression of nonclonally derived progenitors was found in one experiment on fresh cells where almost all colony growth was inhibited (97\%) and also in a second experiment on cryopreserved cells where only a partial (49\%) inhibition was observed. The G6PD A to B ratios of 7:2 and 20:7 in colonies grown from L4F3-treated cells were significantly different from those seen in colonies grown from control-treated cells $(P$ $=0.001$ ). Thus, $\mathrm{L} 4 \mathrm{~F} 3$ and complement treatment of cells from these two patients allowed the expression of presumably normal CFU-GM. The preponderance of A-type colonies after L4F3treatment in patient 2 was also significantly different $(P<0.004)$ from the 1:1 ratio expected on the basis of the G6PD $A$ to $B$ ratio found in normal tissues (19). One explanation for this finding is that selection occurred in vitro for cells whose active $X$ chromosome was the one with $G d^{\mathrm{A}}$. This type of selection has been described in vivo (20-22).

In studies of the other three patients, the ratios of A to B G6PD in colonies cultured after treatment with L4F3 were not different from those in the control colonies; most colonies expressed only the G6PD enzyme found in the leukemic blast cells. This failure to detect an increase in normal progenitor expression occurred even when growth of nearly all of the colonyforming cells was inhibited by L4F3 (patient 3). Thus, lysis of the majority of the CFU-GM did not necessarily predict that the remaining colony-forming cells would be of normal origin. Moreover, a reduction of $<50 \%$ of colonies did not predict that those remaining necessarily would be leukemic (patient 2 , experiment 2).

Long-term culture assays. To assess the nature of the progenitors remaining after antibody treatment, two-stage long-term marrow cultures were established from mononuclear cells after treatment with either L4F3 or T11D7 and complement. The results of several such experiments are summarized in Table III. Irradiated adherent cell layers cultured alone did not develop hematopoietic islands and did not produce CFU-GM. Similarly, CFU-GM were not detectable when irradiated adherent cells were cultured with irradiated normal marrow cells (data not shown), indicating that stimulation of residual stem cells within the irradiated adherent cell layer by an allogeneic reaction was unlikely.

When cells from patient 1 were treated with L4F3 and complement and placed in suspension over irradiated feeder layers, hematopoietic islands were seen by day 7 . In contrast, no morphologic evidence for hematopoietic cell proliferation was observed in the cultures established from T11D7-treated cells. CFUGM were detectable in the supernatant cells of the L4F3-treated cultures by week 1 or 2 . In two separate long-term culture studies on cells from patient 1 , the cumulative culture output of CFUGM from the L4F3-treated cells was substantially greater than that from the control T11D7-treated cells. These differences in colony production reflected both the decay with time of the T11D7 cultures and the increased output of CFU-GM from the L4F3 cultures as they matured.

When L4F3-treated cells from patient 1 were placed in longterm culture, cells obtained 1 wk or more later produced colonies that displayed an A to B G6PD ratio of 74:45, which approximated the $60: 40 \mathrm{~A}$ to $\mathrm{B}$ ratio in skin whereas there was a sig- 
Table III. CFU-GM-derived Colony Growth from Long-term Cultures of Peripheral Blood Cells Treated with Antibody and Complement and Grown on Irradiated Marrow Feeder Layers

\begin{tabular}{|c|c|c|c|c|c|c|}
\hline \multirow[b]{2}{*}{ Culture age } & \multicolumn{3}{|l|}{ Antibody L4F3 } & \multicolumn{3}{|c|}{ Control antibody T11D7 } \\
\hline & $\begin{array}{l}\text { Colonies per } 10^{5} \\
\text { cells plated }\end{array}$ & Colonies per culture* & $\begin{array}{l}\text { G6PD ratio } \\
\text { A to B }\end{array}$ & $\begin{array}{l}\text { Colonies per } 10^{5} \\
\text { cells plated }\end{array}$ & Colonies per culture & $\begin{array}{l}\text { G6PD ratio } \\
\text { A to B }\end{array}$ \\
\hline$w k$ & $n$ & $n$ & & $n$ & $n$ & \\
\hline \multicolumn{7}{|l|}{ Patient 1} \\
\hline \multicolumn{7}{|c|}{ Experiment 2} \\
\hline 0 & $15 \pm 3$ & 150 & $13: 5$ & $60 \pm 5$ & 600 & $18: 2$ \\
\hline 1 & $164^{8}$ & 512 & $18: 10$ & $11^{\S}$ & 189 & $11: 4$ \\
\hline 2 & $290 \pm 290$ & 24 & $10: 11$ & $6 \pm 3$ & 246 & $24: 4$ \\
\hline \multicolumn{7}{|c|}{ Experiment 3} \\
\hline 0 & $13 \pm 7$ & 390 & $10: 5$ & $240 \pm 30$ & 4,700 & $60: 13$ \\
\hline 1 & $2 \pm 2$ & 8 & $10: 2$ & $23 \pm 11$ & 36 & $18: 0$ \\
\hline 2 & $57 \pm 47$ & 114 & $16: 13$ & $44 \pm 12$ & 76 & $21: 5$ \\
\hline 3 & $20 \pm 6$ & 60 & $8: 4$ & $10 \pm 3$ & 21 & $6: 4$ \\
\hline 4 & $280 \pm 12$ & 320 & $12: 5$ & 0 & 0 & NT \\
\hline \multicolumn{7}{|l|}{ Patient 2} \\
\hline \multicolumn{7}{|c|}{ Experiment $2^{\ddagger}$} \\
\hline 0 & $2 \pm 2$ & 20 & $7: 2$ & $4 \pm 3^{\prime \prime}$ & 80 & $3: 16$ \\
\hline 1 & $120 \pm 15$ & 28 & $26: 8$ & NG & 0 & - \\
\hline 2 & $54 \pm 5$ & 40 & $17: 11$ & NG & 0 & - \\
\hline \multicolumn{7}{|c|}{ Experiment 3} \\
\hline & 1 & 1 & & $210 \pm 34$ & 4,200 & $0: 13$ \\
\hline 1 & 70 & 28 & $5: 7$ & NG & 0 & - \\
\hline 2 & 33 & 40 & $6: 5$ & NG & 0 & - \\
\hline 3 & 22 & 44 & $6: 7$ & NG & 0 & - \\
\hline 4 & 62 & 90 & $9: 4$ & NG & 0 & - \\
\hline 5 & 120 & 96 & $20: 7$ & NG & 0 & - \\
\hline 6 & 48 & 96 & NT & NG & 0 & - \\
\hline 7 & 110 & 22 & NT & NG & 0 & - \\
\hline 8 & 30 & 6 & NT & NG & 0 & - \\
\hline \multicolumn{7}{|l|}{ Patient 3} \\
\hline 0 & $3 \pm 1$ & 45 & $0: 11$ & $18 \pm 4$ & 360 & $2: 14$ \\
\hline 1 & $2 \pm 3$ & 4 & $1: 4$ & $38 \pm 13$ & 84 & $1: 6$ \\
\hline 2 & $1 \pm 1$ & 2 & - & $2 \pm 2$ & 10 & - \\
\hline 3 & NG & 0 & - & $3 \pm 1$ & 15 & - \\
\hline 4 & 10 & 6 & $0: 12$ & $13 \pm 7$ & 26 & $0: 6$ \\
\hline 5 & 16 & 8 & $3: 10$ & $29 \pm 12$ & 28 & $4: 8$ \\
\hline 6 & NG & 0 & - & NG & 0 & - \\
\hline \multicolumn{7}{|l|}{ Patient 4} \\
\hline 0 & $70 \pm 7$ & - & $0: 14$ & $65 \pm 15$ & - & $0: 14$ \\
\hline 1 & NG & - & - & NG & - & - \\
\hline 2 & NG & - & - & NG & - & - \\
\hline 3 & NG & - & - & NG & - & - \\
\hline
\end{tabular}

NG, no growth; NT, not tested. * The mean number of colonies per $1.2 \mathrm{ml}$ of long-term tube culture/week. Error bars are not used because the number of cultures was often less than three. The week 0 value represents the number of colony-forming cells added at culture inception. ${ }^{\ddagger}$ Fresh cells. All other experiments were performed using thawed cryopreserved cells. ${ }^{8}$ Only a single plate was available after 1 wk of growth in experiment 2, patient 1. "Many leukemic clusters of $<40$ cells were found at week 0 in experiment 2, patient 2; only colonies of $>40$ cells were picked for G6PD. 'All colonies picked had both A and B G6PD indicating they were not clones.

nificantly higher percentage of colonies from T11D7-treated cultures that expressed type A (80:17), the G6PD found in the blast cells $\left(P<0.01, \chi^{2}\right)$.

Long-term culture studies on antibody-treated cells from patient 2 yielded similar results to those from patient 1. T11D7treated cultures failed to produce significant numbers of colonies whereas L4F3-treated cultures produced substantial numbers of
CFU-GM for 2 and $8 \mathrm{wk}$, respectively, in the two experiments. G6PD analysis of colonies from these cultures showed a preponderance of colonies of the nonleukemic G6PD type. The excess of type A colonies grown from the L4F3 culture of patient 2 confirms the supposition that CFU-GM were not derived from the irradiated, type B, adherent cell layer. The differences between the ratios of $A$ to $B$ colonies grown from the L4F3- and the 
T11D7-treated cultures were statistically significant in all experiments on cells from both patients 1 and $2\left(P<0.01, \chi^{2}\right)$.

Similar experiments were performed on cells from patients 3 and 4 who had failed to express normal CFU-GM in direct culture after treatment with L4F3. When the L4F3-treated cells were established in the two-stage long-term cultures, no morphologic evidence for cell proliferation was observed. Only small numbers of predominantly leukemic colonies were detected.

\section{Discussion}

Previous studies with the G6PD system have demonstrated that AML is a heterogeneous disorder. In some patients with this disease, the same single-enzyme G6PD phenotype found in blast cells was also detected in erythrocytes and platelets, indicating that the leukemia arose in a stem cell with multipotent differentiative expression (10-12). However, in other patients, such as the ones studied here, both A- and B-type G6PD were observed in erythroid cells and platelets, whereas only a single enzyme was seen in the leukemic blast cells (8-10). Two possibilities could underlie this restriction of expression of the clonal abnormality to overtly leukemic cells: first, the leukemia arose in a multipotent stem cell that was at least partially incapable of differentiating into erythroid cells and platelets; or secondly, the leukemic event affected a progenitor that was already committed to granulocyte/monocyte differentiation (10). If this latter hypothesis was correct, even immature malignant progenitor cells could express maturation-linked characteristics similar to those of normal stem cells committed to the myeloid pathway.

The present study was performed to determine whether both the normal and the malignant myeloid colony-forming cells in patients with AML expressed the myeloid differentiation antigen recognized by $L 4 F 3$. This antigen is found on virtually all CFUGM, some BFU-E, and most mixed colony-forming cells (CFUGEMM), but not on stem cells that give rise to CFU-GM in vitro $(6,7)$. Therefore, treatment with an antibody with specificity for this antigen might result in elimination of both normal and malignant colony-forming cells and leave intact a less mature stem cell compartment that does not express the target antigen and may be completely normal in origin. The present findings are consistent with the hypothesis that treatment with L4F3 eliminated malignant colony-forming progenitors in two of the five patients and allowed outgrowth of normal, granulocyte/ monocyte progenitors. Thus, after treatment with $L 4 F 3$, the A to B G6PD ratios of CFU-GM-derived colonies from blood mononuclear cells of patients 1 and 2 were significantly different from those seen after exposure to the control antibody (T11D7), suggesting that the CFU-GM surviving L4F3 treatment were derived at least in part from nonneoplastic progenitors.

In one experiment on cells from patient 2 , the data suggest the possibility that despite an apparent failure of treatment with L4F3 to eliminate most of the colony-forming cells, remaining progenitor cells may be normal (Table II, patient 2, experiment 2). In this experiment, L4F3 decreased colony growth by only 49\%). Nonetheless, the residual CFU-GM were predominantly of G6PD type A although the leukemic clone was type B. This result suggests that the leukemic cells may have inhibited normal stem cell expression.

It is possible that in the samples from patients 1 and 2 mainly nonclonal colony-forming cells remained after lysis because the leukemic progenitors have a higher L4F3 antigen density than the normal progenitors. Similarly, the failure to detect nonclonal progenitors in samples from patients 3-5 could reflect patientto-patient heterogeneity in the density of antigen expression by leukemic progenitors (e.g., if the leukemic progenitors from patients 3-5 expressed a lower L4F3 antigen density that was similar to that on normal progenitors, then lysis with L4F3 might not select for normal cells). However, it is also possible that the results reflect differences from patient to patient in the level of maturity of the leukemic progenitors. It has recently been shown (7) that a pre-colony-forming progenitor that produces both unipotent and multipotent colony-forming cells in long-term cultures does not express the antigen recognized by L4F3. The presence of colonies in cultures of cells from patients 1 and 2 treated with L4F3 and complement, therefore, suggested the possibility that the progenitors for these colonies might be less mature and represent a progenitor population with the capacity to give rise to normal CFU-GM in a permissive environment.

To test this hypothesis, we examined the capacity of cells remaining after treatment with $\mathrm{L} 4 \mathrm{~F} 3$ to give rise to CFU-GM in a two-stage long-term culture system. In this system the adherent cell layer necessary for maintenance of hematopoiesis is provided by normal long-term cultures that are irradiated before the test cells are added. When normal marrow or blood is depleted of colony-forming cells by L4F3 or anti-HLA-DR antibodies and complement, early regeneration of colony-forming cells is observed only in the presence of irradiated adherent cells from normal long-term marrow cultures $(7,17,23)$. These observations support the hypothesis that there are normal stem cells more primitive than those that form colonies, and that these cells do not express the maturation-linked characteristics of colony-forming cells but nevertheless are capable of giving rise to colony-forming cells in long-term culture.

L4F3- and complement-treated cells from patients 1 and 2 placed into two-stage long-term culture gave rise to substantial numbers of CFU-GM, whereas control treated cells did not. From week 1 until the time the cultures were lost, the mean colony frequency in cells harvested from the long-term cultures initiated with L4F3-treated cells from patient 1 was 116 per $10^{5}$ cells. The colony frequency from the L4F3 long-term cultures from patient 2 was 69 per $10^{5}$ cells. In contrast, the mean frequencies of colonies obtained from T11D7 long-term culture supernatant cells were 16 and 0 for patients 1 and 2 , respectively. It can be calculated that the long-term cultures initiated after L4F3 treatment of cells from each of these patients had colony outputs that substantially exceeded the inputs. However, in cultures established after treatment with the irrelevant antibody, T11D7, far fewer colony-forming cells were harvested than were applied.

Colonies cultured after 1 wk in the L4F3-treated long-term cultures from patient 1 had an A to B G6PD ratio of 74:45, close to the 60:40 ratio found in skin. Colonies grown from L4F3-treated cultures from patient 2 manifested A to B G6PD in a ratio of 89:49 whereas the ratio of $A$ to $B$ G6PD in normal tissues was 50:50 and in the blast cells was mainly of the B type, suggesting that they were not derived from the leukemic clone. In contrast, cells from the control antibody T11D7-treated longterm cultures either did not grow (patient 2 ) or formed colonies that expressed predominantly the same G6PD type as the blast cells (patient 1).

The data from patient 2 also suggests that proliferation of normal stem cells in long-term culture was suppressed by cells that expressed the L4F3 antigen. In experiment 1,3 of 19 colonies from the direct cultures of T11D7-treated cells were G6PD type 
A and thus derived from normal stem cells. Therefore, normal colony-forming cells were present in the T11D7-treated cells applied to the long-term cultures and would have been detected had they not been suppressed by the $\mathrm{LAF3}^{+}$cells. These data suggest that in some patients, leukemic, $\mathrm{L}_{4} 3^{+}$cells may inhibit the expression of normal, L4F3- stem cells. This putative inhibition could have been mediated by a factor released by cells or by cell-to-cell contact.

It should be noted that in patient 1 , experiment 3 , and in patient 3 , some colony growth was noted in control cultures and the ratio of G6PD A-type colonies to B-type colonies showed a trend towards the predicted normal ratio of G6PD enzymes (Table III). This finding is consistent with observations by Coulombel et al. (24) and Chang et al. (25), suggesting that merely culturing chronic myelogenous leukemia or AML cells, respectively, may selectively allow expression of normal progenitor cells. However, in experiment 3 for patient 1, lysis with L4F3 also led to production of significantly more colony-forming cells than was seen in control cultures. Furthermore, in other experiments using cells from patients 1 and 2 there was virtually no growth of cells from control cultures.

The expression of normal colony-forming cells or their production in long-term culture was not increased after cells from the other three patients were treated with L4F3. It is possible that in these patients the leukemia arose in less mature cells, which had not yet acquired the myeloid differentiation antigen recognized by $L 4 F 3$. If this occurred in patient 3 , the putative $\mathrm{L} \mathrm{F}^{-}$- leukemic progenitor cells presumably comprised only a small fraction of the leukemic colony-forming cells because L4F3 treatment resulted in a $97 \%$ reduction of leukemic colony growth. Even the small number of unlysed leukemic colony-forming cells in this patient may have been sufficient to inhibit the expression of normal CFU-GM and their precursors. Alternatively, the frequency of normal progenitor cells may have been too low to be detected in our assay system. This possibility is suggested by the inability to culture BFU-E from the blood obtained from patient 4 (only one BFU-E was detected when 2 $\times 10^{6}$ non-antibody-treated mononuclear cells were plated).

These observations may have therapeutic implications. Conceivably, infusion of marrow cells treated in vitro with an antibody such as L4F3 to remove leukemic progenitors might restore normal hematopoiesis even though most colony-forming cells were lost. This occurrence might be especially likely if the remaining pre-colony-forming cells are presumed to be the progenitors required for marrow reconstitution. Thus, marrow treated in vitro with $\mathrm{L} 4 \mathrm{~F} 3$ (or a related antibody) might be useful in autologous transplantation after marrow ablative therapy. However, this suggestion must be tempered by the observations that treatment of marrow with L4F3 may not eliminate the subpopulation of leukemic progenitors, which can grow in vitro. Thus, before optimal strategies for monoclonal antibody treatment of leukemia can be developed, additional studies of malignant progenitor cells and their antigenic phenotypes are needed.

\section{Acknowledgments}

We would like to thank Jerry Peterson, Carrie Stein, and Laura Steinmann for technical assistance, and Tracey Gooding for preparation of the manuscript.

This work was supported in part by grants CA-39492, CA-16448, CA-26828, CA-36011, AM-33298, AM-19410, CA-18029, HL-31782
(National Institutes of Health), and MRC MA8075 (Medical Research Council of Canada). Dr. Keating is a Research Scholar of the National Cancer Institute of Canada.

\section{References}

1. Bernard, A., L. Boumsell, J. Dausset, C. Milstein, and S. F. Schlossman, editors. 1984. Leucocyte Typing: Human Leucocyte Differentiation Antigens Detected by Monoclonal Antibodies. SpringerVerlag, Berlin. 398-403.

2. Bernstein, I. D., and S. Self. 1986. Joint report of the myeloid section of the Second International Workshop. In Leucocyte Typing II. E. Reinherz, B. F. Haynes, L. Nadler, and I. D. Bernstein, editors. Springer-Verlag, New York. 1-20.

3. Ritz, J., S. E. Sallan, R. C. Bast, J. M. Lipton, L. A. Clavell, M. E. Feeney, T. Hercend, D. G. Nathan, and S. F. Schlossman. 1983. Autologous bone marrow transplantation in CALLA positive acute lymphoblastic leukemia after in vitro treatment with $\mathrm{J} 5$ monoclonal antibody and complement. Lancet. ii:60-63.

4. Ramsay, N., T. LeBien, M. Nesbit, P. McGlave, D. Weisdorf, P. Kenyon, D. Hurd, A. Goldman, T. Kim, and J. Kersey. 1985. Autologous marrow transplantation for patients with acute lymphoblastic leukemia in second or subsequent remission: results of bone marrow treated with monoclonal antibodies BA-1, BA-2, BA-3 plus complement. Blood.66: 508-513.

5. Dicke, K. A., G. Spitzer, and A. R. Zander, editors. 1985. Autologous Bone Marrow Transplantation. Proceedings of the First International Symposium. The University of Texas, M. D. Anderson Hospital and Tumor Institute at Houston.

6. Andrews, R. G., B. Torok-Storb, and I. D. Bernstein. 1983. Myeloid-associated differentiation antigens on stem cells and their progeny identified by monoclonal antibodies. Blood.62:124-132.

7. Andrews, R. G., M. Takahashi, G. M. Segal, J. S. Powell, I. D. Bernstein, and J. W. Singer. 1986. The L4F3 antigen is expressed by uni- and multipotent colony forming cells but not by their precursors. Blood. 68:1030-1035.

8. Dinndorf, P. A., R. G. Andrews, D. Benjamin, D. Ridgway, L. Wolff, and I. D. Bernstein, 1986. Expression of normal myeloid-associated antigens by acute leukemia cells. Blood. 67:1048-1053.

9. Fialkow, P. J., J. W. Singer, J. W. Adamson, R. L. Berkow, J. M. Friedman, R. J. Jacobson, and J. W. Moohr. 1979. Acute nonlymphocytic leukemia: expression in cells restricted to granulocytic and monocyte differentiation. N. Engl. J. Med. 301:1-5.

10. Fialkow, P. J., J. W. Singer, J. W. Adamson, K. Vaidya, L. W. Dow, J. Ochs, and J. W. Moohr, 1981. Acute non-lymphocytic leukemia: heterogeneity of stem cell origin. Blood. 57:1068-1073.

11. Fialkow, P. J., and J. W. Singer. 1985. Tracing development and cell lineages in human hemopoietic neoplasia. In I. L. Weissman, editor. Leukemia. Dahlem Konferenzen. Springer-Verlag, Berlin. 203-222.

12. Jacobson, R. J., M. J. Temple, J. W. Singer, W. Raskind, J. Powell, and P. J. Fialkow. 1984. A clonal complete remission in a patient with acute nonlymphocytic leukemia originating in a multipotent stem cell. N. Engl. J. Med. 310:1513-1517.

13. Ferraris, A. M., L. Canepa, and G. F. Gaetani. 1983. Re-expression of normal stem cells in erythroleukemia during remission. Blood. 62: 177-179.

14. Ferraris, A. M., G. Broccia, T. Meloni, L. Canepa, M. Sessarego, and G. F. Gaetani. 1984. Clonal origin of cells restricted to monocytic differentiation in acute nonlymphocytic leukemia. Blood. 64:817-820.

15. Griffin, J. D., D. Linch, K. Sabbath, P. Larcom, and S. F. Schlossman. 1984. A monoclonal antibody reactive with normal and leukemic human myeloid progenitor cells. Leuk. Res. 8:521-534.

16. Singer, J. W., P. J. Fialkow, L. W. Dow, C. Ernst, and L. Steinmann. 1979. Unicellular or multicellular origin of granulocyte/monocyte colonies in vitro. Blood. 54:1395-1399.

17. Takahashi, M., A. Keating, and J. W. Singer. 1985. A functional 
defect in irradiated adherent layers from chronic myelogenous leukemia long-term marrow cultures. Exp. Hematol. 13:926-931.

18. Gart, J. J. 1971. The comparison of proportions: a review of significance tests, confidence intervals and adjustments for stratification. Rev. Int. Stat. Inst. 39:148-169.

19. Fialkow, P. J. 1973. Primordial cell pool size and lineage relationships of five human cell types. Ann. Hum. Genet. 37:39. (Abstr.)

20. Nyhan, W. L., B. Bakay, J. D. Conner, J. F. Marks, and D. K. Keele. 1970. Hemizygous expression of glucose-6-phosphate dehydrogenase in erythrocytes of heterozygotes for the Lesch-Nyhan syndrome. Proc. Natl. Acad. Sci. USA. 65:214-218.

21. Prchal, J. T., A. F. Carroll, J. F. Prchal, W. M. Crist, H. W. Skalka, W. F. Gealy, J. Harley, and A. Malluh. 1980. Wiskott-Aldrich syndrome: cellular impairments and their implication for carrier detection. Blood. 56:1048-1054.

22. Gealy, W. J., J. M. Dwyer, and J. B. Harley. 1980. Allelic exclusion of glucose-6-phosphate dehydrogenase in platelets and T-lymphocytes from a Wiskott-Aldrich syndrome carrier. Lancet. i:63-65.

23. Moore, M. A. S., H. E. Broxmeyer, A. P. C. Shendon, P. A. Meyers, N. Jacobson, and R. J. Winchester. 1980. Continuous human bone marrow culture: Ia antigen characterization of probable pluripotential stem cells. Blood. 55:682-690.

24. Coulombel, L., D. K. Kalousek, C. J. Eaves, C. M. Gupta, and A. C. Eaves. 1983. Long-term marrow culture reveals chromosomally normal hematopoietic progenitor cells in patients with Philadelphia chromosome-positive chronic myelogenous leukemia. N. Engl. J. Med. 308:1493-1498.

25. Chang, J., L. Coutinho, G. Morgenstern, J. H. Scarffe, D. Deakin, C. Harrison, N. G. Testa, and T. M. Dexter. 1986. Reconstitution of haemopoietic system with autologous marrow taken during relapse of acute myeloblastic leukaemia and grown in long-term culture. Lancet. 8:294-295. 